Georgia State University

ScholarWorks @ Georgia State University

$11-17-2016$

\title{
Comparing Help-Seeking Behavior of Male and Female Survivors of Sexual Assault: A Content Analysis of a Hotline
}

Stephen M. Young

Jana Anne Pruett

Follow this and additional works at: https://scholarworks.gsu.edu/ghpc_articles

\section{Recommended Citation}

Young, Stephen M. and Pruett, Jana Anne, "Comparing Help-Seeking Behavior of Male and Female Survivors of Sexual Assault: A Content Analysis of a Hotline" (2016). GHPC Articles. 49.

https://scholarworks.gsu.edu/ghpc_articles/49

This Article is brought to you for free and open access by the Georgia Health Policy Center at ScholarWorks @ Georgia State University. It has been accepted for inclusion in GHPC Articles by an authorized administrator of ScholarWorks@Georgia State University. For more information, please contact scholarworks@gsu.edu. 
Comparing Help-Seeking Behavior of Male and Female Survivors of Sexual Assault: A Content Analysis of a Hotline
Sexual Abuse: A Journal of Research and Treatment

$|-2|$

(C) The Author(s) 2016 Reprints and permissions: sagepub.com/journalsPermissions.nav DOI: I0.1I77/I0790632I6677785 sax.sagepub.com 丹SAGE

\title{
Stephen M. Young', Jana A. Pruett², and Marianna L. Colvin ${ }^{3}$
}

\begin{abstract}
This content analysis examines written documentation of telephone calls to a regional sexual assault hotline over a 5 -year period. All male callers identified as primary victims were selected for analysis $(n=58)$ and a corresponding sample of female primary victims $(n=58)$ were randomly selected for comparison to better understand the help-seeking behavior of sexual assault survivors and inform services accordingly. A summative content analysis revealed significant contrasting themes between male and female victims, including females significantly receiving more referrals and males accessing the hotline to tell their experience of being sexually assaulted due to perceived limited support. Implications for training, practice, and future research are discussed.
\end{abstract}

\section{Keywords}

sexual assault, hotline, male, female, rape, help seeking

In the United States, $18.3 \%$ of women (almost 1 in 5) and 1.4\% of men (1 in 71) have been raped according to the National Intimate Partner and Sexual Violence Survey (Black et al., 2011). In the same study, 5.6\% of women and 5.3\% of men reported experiencing sexual violence (other than rape) within 12 months of the survey (e.g., sexual coercion, unwanted sexual contact, non-contact unwanted sexual experiences,

\footnotetext{
'University of South Alabama, Mobile, AL, USA

2University of Georgia, Athens, GA, USA

${ }^{3}$ Florida Atlantic University, Boca Raton, FL, USA

\section{Corresponding Author:}

Stephen M. Young, University of South Alabama, 599I USA Drive N., Mobile, AL 36688, USA.

Email: smyoung@southalabama.edu
} 
etc.; Black et al., 2011). A study examining data from the Bureau of Justice Statistics (BJS), Centers for Disease Control and Prevention, and the Federal Bureau of Investigation indicates an alarming number of sexual victimizations of both genders at much the same rate as each other, explaining that previous studies had methodological issues that contributed to the underrepresentation of male victims (Stemple \& Meyer, 2014). Although these statistics are substantial, researchers suggest that statistics underrepresent the actual number of sexual assaults occurring due to men and women's sense of shame around the incident, hesitancy to access services, and social stigma of sexual victimhood (Tjaden \& Thoennes, 2006). The BJS estimates that about $65 \%$ of sexual assaults went unreported from 2006 to 2010 (BJS, 2012).

The trauma experienced from sexual assault can lead to serious and long-lasting negative consequences for survivors, particularly when left untreated (Finn, Garner, \& Wilson, 2011). In addition to the immediate physical and emotional harm caused by rape, symptoms suffered by men and women who experience sexual assault include low self-esteem, depression, antisocial behavior, substance abuse, risk-taking, and self-harming behavior (Finn \& Hughes, 2008; Krebs, Linquist, Wanrner, Fisher, \& Martin, 2009). Survivors of rape are also 13 times more likely to attempt suicide than the general population and 6 times more likely than victims of other crimes (Tjaden \& Thoennes, 2006). As such, the trauma of sexual assault should be met with the adequate provision of timely services that address short- and long-term emotional and physical needs of both male and female survivors. However, due to a lack of specific research on supporting male survivors, this study compares the helpseeking behaviors of males with females to better understand how sexual assault may affect these groups differently to highlight the specific treatment needs of male survivors. In addition, in this study the terms victim and survivor are used interchangeably. Based on extant literature, the term survivor conveys the strength of persons who have been assaulted while the term victim reflects the actual criminal nature of the act.

\section{The Literature Gap}

Sexual assault literature and research informed interventions are largely focused on sexual violence against women, and few studies have compared men's sexual victimization experiences and help-seeking behavior with those of women (Stemple \& Meyer, 2014). The paucity of research on male victims may be due not only to men constituting such a small percentage of reported sexual assaults, but also because of the ways in which sexual violence has been theoretically, socially, and legally operationalized over time (Bierie \& Davis-Siegel, 2015; Stemple \& Meyer, 2014; Weiss, 2009). For example, until the 1980s, the majority of rape laws in the United States discounted the potential of males to be victims by explicitly outlining rape as a crime committed against women. In addition, activists and feminist scholars have framed rape and sexual assault as fundamentally a women's health issue within the larger violence against women literature. These constructs of attributing sexual violence to men's nature or their socialization are so well established that imagining men 
as victims of rape or women as sexual aggressors requires a mindful disconnect of preconceived ideas about gender and sexual violence (Weiss, 2009). The operationalization of sexual victimization, the female victim/male perpetrator paradigm, and sampling biases that do not include inmates, have all contributed to underrepresentation of male victims in national prevalence studies (Stemple \& Meyer, 2014). Therefore, it is not surprising that historically, prevalence studies and other empirical research on sexual violence focus almost exclusively on female victims (Doherty \& Anderson, 2004; Holmes, Offen, \& Waller, 1997; Weiss, 2009). It should be noted that literature on male sexual victimization has grown steadily since the 1980 s, suggesting that the sexual assault of men is not as rare as the earlier dearth of evidence indicated.

Studies that have compared male and female sexual assault victims found that attacks occur more frequently with younger victims (mostly in their 20s to early 30s) regardless of the sex of the victim (Elliott, Mok, \& Briere, 2004; Frazier, 1993; McLean, 2013; Riggs, Houry, Long, Markovchick, \& Feldhaus, 2000), and some research suggests that male victims are more likely to have more than one assailant than female victims (Frazier, 1993; Riggs et al., 2000). The strong stigma of being a male and a victim of sexual assault may explain why men are less likely than women to disclose to friends and family and seek help after an assault (Holmes et al., 1997) and may be more likely to use hotlines, due to their anonymous nature, than other resources (Colvin, Pruett, Young, \& Holosko, 2016).

\section{Sexual Assault Hotlines}

Since the 1970s, sexual assault hotlines have grown in popularity in North America as effective channels, whereby survivors, their loved ones, and professionals come together to provide crisis support and urgent linkages to services within the community. The Rape, Abuse, and Incest National Network (RAINN) identified 1,065 crisis hotline affiliates in operation in the United States (RAINN, 2013). Empirical research about sexual assault hotlines is limited and much remains unknown or unclear about their efficacy as crisis counseling modalities despite their wide utilization (Resnick, Acierno, Kilpatrick, \& Holmes, 2005; Wasco et al., 2004). These gaps in knowledge pose a troubling challenge in our current political and economic environment where evidence-based practices are highly desired to inform professional fields of practice and allocate limited funds (Finn \& Hughes, 2008; Resnick et al., 2005; Wasco et al., 2004). In addition, research is needed to illuminate and capitalize on the unique potential of hotlines in terms of their expansive community reach, diverse clientele, immediate accessibility, and anonymous nature.

For traumatic events in general, telephone hotlines play an important role in providing immediate support for survivors. However, service providers in other sectors (e.g., health care, legal services, etc.) either lack training or do not offer traumainformed services to address problems associated with sexual violence (Elliott, Bjelajac, Fallot, Markoff, \& Reed, 2005). Thus, sexual assault hotlines fill a critical community service niche. 


\section{Purpose}

As research of sexual violence has been conducted predominantly with females, limited empirically informed interventions are available to support male victim-survivors. Specifically, despite the fact that sexual violence is not a gendered issue, we know relatively little about males' experiences. The purpose of this study is to compare the documented call narratives of male sexual assault victims with female sexual assault victims who called a telephone hotline, with the intent to better understand the helpseeking behavior and experiences of male sexual assault victims and inform services accordingly. Points of analyses were derived from hotline call documentation and included themes regarding implied beliefs, emotional expressions, contradictions (evidenced by documented beliefs and behaviors), and services requested. As the anonymity of hotline services may further their use by male victim-survivors, hotline documentation offers an opportunity for understanding this population.

\section{Method}

\section{Sample}

A retrospective analysis of archival data was performed using the documentation of hotline calls from a sexual assault center (SAC) located in the South Eastern United States. The agency in this analysis serves a multi-county region, including a university town, with an estimated population in 2010 of about 117,000, and a concentrated student population (U.S. Census Bureau, 2014). The agency offers a multitude of services for survivors, friends and family members, and professionals. These include free and confidential medical and legal advocacy, an adult survivor support group, counseling referrals for survivors, and support for secondary survivors. Volunteers and agency employees staff the hotline. Required training includes information on the prevalence and impact of sexual assault and harassment, as well as training on crisis intervention.

Referred to herein as "call sheets," documentation of hotline calls from January 2008 through December 2012 comprised the sampling frame $(N=1,970)$. Each call sheet was numbered to provide a unique identifier. All call sheets labeling a male as the primary victim-survivor (i.e., victims calling the hotline for themselves) were identified from the sampling frame and were reviewed by a member of the research team. Excluded from this analysis were calls by males determined to be a professional (i.e., law enforcement, etc.), males calling about someone else, and those identified by hotline workers or researchers to likely be prank phone calls. The remaining call sheets were then reviewed and verified to be primary victims by a second researcher, resulting in 58 identified call sheets documenting calls made by male primary victim-survivors or $2.9 \%$ of all calls over a 5-year period. A sample of female primary victim-survivors $(n=58)$ was then selected for comparison using a random number generator in Microsoft Excel. The first 58 random numbers that corresponded with call sheets identifying primary female primary victim-survivors were selected as the comparison sample, other random numbers were skipped. 


\section{Procedure}

Mixed-methods were used to analyze data. The majority of quantitative variables were directly transposed from information routinely collected by the agency (e.g., call duration, sex of victim, age of victim, and date of assault). In addition, a written summary description of each call allowed the authors to rate call severity and urgency. Details of what happened during the call and the documented expressions of the caller were also noted from summary information, as well as details of what was provided to each caller in terms of an advocate, information, referrals, and/or empathy. In all, the following variables were included in analyses.

\section{Quantitative Variables Included Within Analysis}

1. Duration: The start and end time of each call was used to measure duration in minutes. Designation of a.m./p.m. was included on the call sheets, but not routinely filled out, and therefore the time of day could not be examined.

2. Sex: The sex of victim was dichotomous, male or female. The gender of the victim was not collected at the time of the call.

3. Age: The age of victim was recorded as a scale level variable, in years. Age was recoded into a categorical variable for analysis as follows, age 0 to 17 , age 18 to 24 , and age 25 and older. These choices were made to identify the prevalence of minor victims, as well as victims in the young adult age range per the local university population.

4. The date of assault was used for coding the time frame between sexual assault and the date of the hotline call as follows: within $72 \mathrm{hr}, 72 \mathrm{hr}$ to 1 week, 1 week to 1 month, 1 month to 1 year, 1 to 3 years, or more than 3 years.

5. Using the descriptive summary written on each call sheet, the research team ranked each call for severity on a 5-point Likert-type scale with $1=$ low severity and $5=$ high severity. Scores of 1 and 2 were combined to represent low severity, scores of 3 represented moderate severity, and scores of 4 and 5 represented high severity. A caller reporting a recent sexual assault with physical contact was rated as a 5. Callers describing suicidal ideation and other forms of self-harm, immediate safety concerns, and/or extreme life interference were also rated as a 4 or 5 . The authors did not assume that a sexual assault with physical contact created severe psychological distress or suicidal ideations, or that sexual assault without physical contact did not cause severe psychological distress. Therefore these factors, both together and separate, could contribute to a designation of high severity. Examples of a rating of 3 include someone reporting that they were in services, but still experiencing some discomfort or distress due to a past assault or discomfort due to ongoing sexual harassment. Finally, informational calls without any report of sexual assault or the need for emotional support would rate a 1 or 2. In some instances, discussion was needed to arrive at a consensual use of the rating system. 
6. Each call was also rated as either urgent or not urgent. Urgent calls were defined as requiring a form of immediate action on the part of the hotline staff or volunteer, such as referral to an advocate or law enforcement.

7. What was provided to each caller was also identified. The authors designated the following categories: information, empathy, advocate, referral, or law enforcement. More than one category could apply.

A process of inter-rater reliability was conducted by the researchers using a random sample of 30 call sheets ( $84 \%+$ agreement) for establishing confidence in the reliability of data interpretation for quantitative variables. When discrepancies occurred, researchers convened to clarify and reach congruence on all study variables.

\section{Qualitative Analysis}

A summative content analysis method was chosen for analyzing this data source. This method is noted to be useful for text that is complex or that covers sensitive topic areas (Rapport, 2010), as "the review of documents is an unobtrusive method, rich in portraying the values and beliefs of participants" (Marshall \& Rossman, 1999, p. 116). In qualitative research, trustworthiness is established by using well-grounded methods (Guba \& Lincoln, 2005), including developing an early familiarity with the participating organization, triangulation, frequent debriefing among researchers, peer scrutiny, thick description in the findings (Shenton, 2003), and maintaining a detailed audit trail (Guba \& Lincoln, 2005). Each member of the research team has experience in clinical social work and professional experience working with survivors of sexual assault and one has extensive experience in hotline training and administration. All were independent of the agency under study. Debriefing sessions were conducted at every stage of analysis by the research team and an audit trail was kept documenting each researcher's analysis process and impressions during coding. Rich quotes were included in the findings to support how the themes were derived and to facilitate their transferability by readers (Creswell, 2007). During analysis, quotes were tagged with a unique identifier in a separate document, so that they could be traced back to specific call sheets for context.

As recommended (Bogdan \& Biklen, 1982), the narratives were read once before coding began for the researchers to familiarize themselves with the data. This was also done to gain a better overall perspective of the context, as well as the perceptions and experiences of hotline callers to reduce the influence of a researcher's own subjective opinions during analysis of the data. Per the insights of this review and the intent to capture the experiences of male victim-survivors, the following five overarching coding categories were established: "beliefs about self," "beliefs about others," "emotions expressed/experienced," "services requested/needs," and "contradictions." Contradictions were specifically identified and coded as a strategy to prevent potential disruptions or skewed findings, as advised by Creswell (2007).

Each researcher individually coded the narrative portions of hotline call sheets into the five defined categories. The narrative portion on the call sheets enabled the use of 
language in a more precise way to convey the experiences of the victim and, in the first stage of coding, each researcher coded exact phrases, unaltered, for initial consideration. For example, the phrase "distrusts the church because of a childhood molestation" was coded under beliefs about others and the phrase "he was not sure if he wanted to press charges" was coded under emotions expressed. Coding was then crosschecked by the three researchers. This method was used to avoid biases in the development of codes per the researcher's prior knowledge, beliefs, and perceptions.

In the second stage of analysis, the codes were grouped and summarized. The relationships between codes were considered, in some cases leading to the amalgamation of separate categories under a superordinate group. Ryan and Bernard's (2003) techniques for identifying themes from basic expressions in the text were used. Themes were identified independently by each researcher, and consensus was established through group discussion, focusing on specific excerpts. For example, the phrase referenced above, "he was not sure if he wanted to press charges," was grouped in this stage with other phrases that similarly expressed confusion among callers. Note that code counting was not routinely applied in analysis, as "a count conveys that all codes should be given equal emphasis" (Creswell, 2007, p. 152), yet the degree to which a belief is held or an emotion expressed varies. Frequency counts, however, were applied for behavioral codes (e.g., abrupt hang-ups) to quantify their prevalence of occurrence.

The same initial coding process and categories were used to analyze the sample of call sheets pertaining to female callers. Several findings were immediately evident due to the contrast between the themes in the male caller sample versus the female caller sample. The research team then conducted a third stage of analysis to examine themes with gender contrasts in mind to better understand the intricacies of this divergence. In this process, it became apparent that while theme development was guided by the original five coding categories, prominent themes highlighted the unique experiences of male victim-survivors distinctive from female victim-survivors. The structure of results likewise informs the experiences of female victim-survivors and achieves a more holistic representation of hotline usage. The institutional review board at the University of Georgia approved this project. All identifying information was removed from call sheets to further protect anonymity.

\section{Findings}

This study analyzed call sheets for both male $(n=58)$ and female $(n=58)$ callers. When age was recorded $(n=43)$, callers ranged from 15 to 61 years $(M=32$, median $=25, S D=14.22)$. Of the total sample $(n=116)$, calls lasted on average just under 15 $\min (M=14.4$, median $=12.5, S D=13.31)$. The time between the reported assault and contacting the hotline had a bimodal distribution, with $29.1 \%$ of calls occurring less than $72 \mathrm{hr}$ post-assault, and $34.9 \%$ of calls occurring 3 or more years post-assault. Significant findings from quantitative data are reported alongside the qualitative themes and summarized in Table 1. There were no significant differences found between male and female callers regarding the severity of calls, if empathy was 
Table I. Significant Chi-Square Differences.

\begin{tabular}{|c|c|c|c|c|}
\hline & $\begin{array}{c}\text { Available } \\
n\end{array}$ & Female \% & Male \% & $\chi^{2}$ \\
\hline Call duration & 116 & & & $3.914 *$ \\
\hline 5 min or less & & 24.1 & 41.4 & \\
\hline More than 5 min & & 75.9 & 58.6 & \\
\hline Referrals made & 116 & & & $5.327^{*}$ \\
\hline No & & 63.8 & 82.8 & \\
\hline Yes & & 36.2 & 17.2 & \\
\hline Advocate & 115 & & & $5.610 *$ \\
\hline No & & 67.2 & 86.0 & \\
\hline Yes & & 32.8 & 14.0 & \\
\hline Urgency & 116 & & & $4.957^{*}$ \\
\hline Not urgent & & 69.0 & 86.2 & \\
\hline Urgent & & 31.0 & 13.8 & \\
\hline
\end{tabular}

Note. 0 cells have an expected count less than 5 . No significant difference: severity, empathy, information, age of victim, date of assault.

*Significant at the .05 level.

Table 2. Qualitative Themes.

\begin{tabular}{ll}
\hline Females & \multicolumn{1}{c}{ Males } \\
\hline $\begin{array}{l}\text { Hotline used as additional support supplement } \\
\text { family, friends, and professionals }\end{array}$ & Hotline used due to limited or no support \\
Used to access a variety of resources & Used to access counseling only \\
$\begin{array}{l}\text { Openly discussed thoughts of suicide and/or } \\
\text { self-harm }\end{array}$ & $\begin{array}{c}\text { Difficulty expressing thoughts and feelings } \\
\text { with apparent distrust of others }\end{array}$ \\
$\begin{array}{ll}\text { Suspected drug-facilitated sexual assault } & \text { Confusion around boundaries } \\
\text { Concerned about being believed } & \end{array}$ \\
\hline
\end{tabular}

provided, if information was provided, the age of victim, or the time lapse in contacting the hotline in relation to the date of sexual assault.

Qualitative data revealed contrasting themes between male and female victimsurvivors' usage of hotlines, including the use of social support or lack thereof, service-seeking behavior, and expressing thoughts and feelings. For a brief synopsis of themes, see Table 2. Details of these findings are presented with quotations drawn directly from the narrative section of the call sheets.

\section{Male Callers}

Hotline used due to limited or no support. Many male callers accessed the hotline to tell their experience of being sexually assaulted, often for the first time. In these instances, 
male callers rarely sought formal counseling or additional services, other than an opportunity to tell their story as illustrated in the following example.

[Caller] was assaulted last year. This was his first time really telling anyone what happened and was feeling guilty and confused. I offered to take down his number and have one of the advocates call [him back], but he was really uneasy about that. (Male, 18 years old)

The desire to tell one's story is not unique to victims of sexual assault. However, the inner conflict of wanting to articulate and share a deep, potentially traumatic, and personal experience and yet remain anonymous appears to be a common experience for male survivors of sexual assault.

The male caller told me he just needed to talk to someone because he couldn't talk to his family. I asked him to tell me a bit about what he was feeling. After a long silence he told me he was assaulted on the previous night. I asked him since the assault occurred less than 72 hours ago [would he] like more information about what his options were. The caller hung up. (Male, age unknown)

While these conversations require skillful communication to best support callers, they do not often require immediate action on the part of the hotline staff or volunteer to make a referral to an advocate or law enforcement; and therefore, were not identified as urgent (as defined in this study). Only $13.8 \%$ of calls made by male victims were identified as urgent compared with $31 \%$ of female victims $\left(\chi^{2}=4.96, d f=1, N=\right.$ $116, p<.05)$. Nevertheless, hotline workers regularly documented their attempts to validate and normalize male callers' experiences of confusion surrounding the incident and complex feelings, such as disgust, guilt, shame, and self-blame. However, despite wanting feelings validated or having a desire to speak to a counselor or hotline worker, some male callers still found it difficult to open up.

[Caller] called to talk about his feelings due to an incident he called rape. He said he feels embarrassed \& guilty for the incident. [I] validated his feelings \& asked how he deals w/ these feelings. He said he has repressed them but wants to talk about the incident but not in a counseling setting. He sounded as if he was unsure of what to say. [I] told him that it was ok to feel this way. He hung up. (Male, age unknown)

Used to access counseling only. Male callers largely used the hotline to access crisis counseling and/or as a referral source for formal counseling services. Unlike their female counterparts, males did not seem to know of or seek agency services or community resources outside of counseling. When male callers were specifically looking for a referral for formal counseling, they were often very direct about their purpose for calling and did not disclose personal information to the hotline workers.

Caller stated he was a victim of rape about 3 weeks ago and wanted to be put in contact with a counseling service. (Male, age unknown) 
Caller wanted a therapeutic referral. He stated that the assault happened a while ago. (Male, age unknown)

Moreover, when presented with additional resources, men would often decline these services even when resources were readily available. Again, the quantitative finding that females were significantly more likely to receive referrals than males $\left(\chi^{2}=5.33, d f=1, N=116, p<.05\right)$ lends support to this theme.

Male victim called saying he was assaulted a few months ago and was tired of holding it all in and wanted to talk to someone. He said that he was at a party with some friends. $[\mathrm{He}]$ started feeling ill and laid down. When he woke up, his pants and underwear were off. The caller asked my advice and when [I started to discuss] the services the [host agency] offers, he abruptly hung up. He did not give a number or contact information. (Male, age unknown)

Distrust of others. A strong distrust of others was evident among male callers. This distrust included people in both their personal (e.g., friends, family, etc.) and professional networks (e.g., hotline workers and other professionals) as demonstrated in the examples below.

The call started with [caller] telling me that he was abused as a child and that he was just having a bad day today. He has a non-existent support system, but he prefers to keep this part of his life secretive. I asked him if he wanted a number that could link him to counseling services and he abruptly hung up. (Male, 42 years old)

While a distrust of others was occasionally displayed by female callers who sometimes declined to provide personal information, it was pervasive among male callers and was reinforced through documented behaviors that conveyed hesitation by male callers (e.g., long pauses and avoiding questions) and abruptly hanging up the phone. For example, the call narrative below documented the caller's hesitation to openly share with the hotline worker, ending with an unexpected hang-up.

He mentioned that he felt disgusting. I tried to calm him and tell him he did nothing wrong but he was very quiet. He wasn't talking much and tried to avoid answering my questions. Then he abruptly hung up the phone. (Male, age unknown)

Abrupt hang-ups were documented in $25.9 \%$ of male calls (15 out of 58), compared with $3.4 \%$ of female calls ( 2 out of 58 ). This may have been a factor in lessening the time spent by males on hotline calls, which was found to be significantly lower than females. Only $24.1 \%$ of female callers stayed on the phone for $5 \mathrm{~min}$ or less compared with $41.4 \%$ of male callers $\left(\chi^{2}=3.91, d f=1, N=116, p<.05\right)$. The often-short duration of calls, combined with the reduced ability of hotline workers to offer support when a caller is guarded may be limiting male callers in how they use and benefit from hotline services. 
Caller wanted to discuss his assault. He conveyed he met a woman through [website]. He conveyed they met and she took things too far, but did not go into detail. He expressed his frustration about not being able to tell anyone because they would not understand. $\mathrm{He}$ conveyed he would call back if he decided he wanted counseling. Caller ended call abruptly. (Male, 44 years old)

Moreover, the struggle of male callers to overcome distrust to access services was apparent, even when they specifically vocalized a need.

Caller stated that he needed to talk to an advocate. Stated he was assaulted and it was very difficult to talk about. Caller hung up, called back, and immediately hung up again. (Male, age unknown)

Confusion around boundaries. Both male and female callers questioned what constituted sexual assault. For example, in some instances callers consented to particular sexual activities but did not consent to others. However, males in this study were much less likely to disclose personal information, so their openness about their confusion around boundaries or minimization of the incident stood out as significant for men who have experienced sexual assault.

[Caller] felt very uncomfortable because earlier in the night he took some pill that he believes to be ecstasy and a friend of his aunt seduced him. He was a virgin until the occurrence and felt very guilty about his choice. I recognized the authenticity of the call because his voice was very shaky and he had no intention other than receiving counseling. I explained to him that contrary to his own beliefs, sexual assault can happen to anyone and that the [host agency] can provide a variety of services along with accompaniment for reporting. He said he didn't want to report because he is a guy even though I explained to him that he should not feel a hindrance because of his gender. I also asked him about his support system and he says that he is going to talk to his best friend, a girl named [friend]. He doesn't feel comfortable talking to any male friends. (Male, 19 years old)

\section{Female Callers}

Hotline used as additional support. It was evident that female callers often confide to those in their social support networks (i.e., friends and family) before contacting the hotline for formal support. Rarely was the hotline their first point of contact after the sexual assault incident. For example, in the following excerpt, the caller had previously disclosed to her mother before contacting the hotline.

[Caller] first talked about her ruined family/friend relationships due to a case she was taking to court about her best friend's husband sexually assaulting her. [She] decided (on her own) to drop case. She was very overwhelmed. Mom frequently calls her a liar and believes she is fabricating emotions and story. [She] wants to move out. I gave her [information for housing assistance]. (Female, 36 years old) 
Female callers were often in formal services already. Regardless of having formal and informal support in place, these callers mentioned feeling "overwhelmed." They knew the hotline was an option when they needed extra or skilled support (e.g., crisis counseling, suicide assessments, etc.) and they seemed to access the hotline as an extended support network of persons who were likely more knowledgeable about sexual assault and more available (24/7 service) than their personal support networks.

[Caller] is currently receiving services from [host agency] and attending group sessions. She called b/c she was feeling sad and lonely and just needed reassurance that she wasn't alone in this recovery process. I comforted her and gave her some support and she was very thankful for that. She said she was so thankful for the hotline, for [specific worker]'s assistance, \& her group therapy sessions. She was sad that there wouldn't be [a] group meeting this week. She just needed some encouragement and a listening ear. (Female, age unknown)

Used hotline to access a variety of resources. Females, more so than males, were aware of and actively seeking a wide variety of services available to them (e.g., drug testing, rape-kits, self-defense, abortion clinics, testing for sexually transmitted infections, food, housing options, etc.). They knew that services existed in their community and sought support in accessing specific resources.

Caller was raped 2 months ago and is pregnant as result of the rape. Caller wants an abortion and needs assistance in locating an agency. Financial needs as well. (Female, 20 years old)

This theme was reinforced with a quantitative measure of whether a referral was provided on the call (i.e., "yes" or "no"), with females significantly more likely to receive referrals than males $\left(\chi^{2}=5.33, d f=1, N=116, p<.05\right)$. In addition, advocate services were provided to $32.8 \%$ of female callers compared with $14.0 \%$ of male callers $\left(\chi^{2}=5.61, d f=1, N=115, p<.05\right)$.

Openly discussed thoughts of suicide and/or self-harm. While both male and female callers discussed thoughts of suicide and self-harm, female callers were consistently more open about their thoughts about self-harming (e.g., cutting, scratching, hitting oneself, etc.). Females were more likely to discuss feelings of being overwhelmed, and they would often incorporate their history of self-harm and suicidal thoughts into their narratives of the healing process.

Tonight in her counseling session she revealed what happened to her for the first time. She said she felt a lot worse after sharing. She told me she used to cut, and tonight on a scale from 1-10 she was at a 5 for wanting to cut again. She said she scratched her skin, but didn't make herself bleed. She was worried that I would tell the police. (Female, 18 years old)

Suspected drug-facilitated sexual assault. The term date rape drug is used colloquially and was used frequently on the call sheets. However, "date rape" can be misleading 
because the person who commits the crime might not be dating the victim of sexual assault, rather the perpetrator could be an acquaintance or a stranger. Therefore, the term drug-facilitated sexual assault will be referenced here. While drug-facilitated sexual assault can happen to both sexes, no male callers in our study mentioned the possibility of being intentionally drugged. However, this emerged as a strong theme among female callers as many women specifically questioned the possibility of drug involvement.

Caller wanted to know if it was possible to be tested to see if she had been given any drugs/date raped. I told her that after $72 \mathrm{hrs}$ it was not likely that they would be able to find any traces of drugs. She had already had tests run but was not sure what they tested. I told her the police and nurses would have the information from her [rape] kit [results]. (Female, age unknown)

Concerned about being believed. Some female callers vocalized distress due to not being believed by loved ones (e.g., mother, boyfriend, husband, etc.) or professionals (e.g., law enforcement, etc.) about being sexually assaulted. In these instances, the hotline functioned as a source of support and guidance for women.

[Caller] has been raped 3 times, can't sleep, \& has no one to talk to. (Her husband tells her the rapes are her fault.). (Female, 45 years old)

In addition, some women expressed concern over intentionally using drugs or alcohol before the assault occurred and now were being blamed for the incident or not being believed by family, friends, or professionals.

[Caller] was very concerned because she was raped 3 weeks ago and reported the crime to the police, but now the fact that she had smoked crack cocaine the night of the rape has come out. She feels like the detective doesn't believe her now that this has come to light, and the detective told her that this evidence was going to make the case against the perpetrator more difficult. (Female, 41 years old)

\section{Discussion}

The males in this study used the hotline specifically for crisis counseling or counseling referrals without receiving other referrals for services. Possibly, men may be more comfortable sharing their experiences in anonymous or private, one-on-one, settings such as counseling rather than in a group setting. In addition, men may be hesitant to seek services in community settings (i.e., hospitals, shelters, etc.) and display their victim status to non-essential persons. For example, males who contemplate attending a hospital or clinic for a rape examination may fear facing judgment from people who may be aware of their victimhood but are not directly involved in the medical exam (e.g., administrative support, non-essential nurses, or physicians).

Male callers were also more likely to demonstrate a strong distrust of others, as evidenced by their hesitancy to disclose to others and their tendency to abruptly hang 
up on hotline workers. Lisak (1994) labels these beliefs about others as "negative schemas about people" and the resulting behavior as "isolation and alienation." Research suggests that male sexual assault survivors are concerned about the unpredictable responses from others or doubt that any form of help will be provided if they do disclose (Easton, Saltzman, \& Willis, 2014). In Easton et al.'s (2014) content analysis of 460 men who disclosed histories of child sexual abuse, the researchers found a "mistrust of others" as a common theme of male survivors of sexual assault. Easton and his colleagues (2014) write

... the decision-making process surrounding disclosure often involves weighing the potential risks and benefits associated with telling others about the sexual abuse. Men who made prior disclosures relied heavily on their previous experiences (which were often negative) when considering whether to disclose again. (p. 468)

Abruptly hanging up could be a way male victims are demonstrating their frustration and distrust of others, fearing they will be judged or not understood. This distrust of others was evidenced in the current study as being a significant barrier for males seeking support services. In fact, in a study of 219 males who were sexually assaulted, those who were penetrated had significantly lower odds of seeking counseling than those who were sexually assaulted in another way (Monk-Turner \& Light, 2010).

While similar barriers may affect both male and female survivors from seeking support services, there are likely unique factors that specifically inhibit males from reaching out for support (Sorsoli, Kia-Keating, \& Grossman, 2008). Researchers of male sexual assault survivors theorize that men's victimization undermines the prevailing norms of masculinity. Research on men's psychology and health behavior suggests a strong identification with masculine norms (e.g., emotional control, self-reliance, etc.; Mahalik et al., 2003) is correlated with a wide range of health-related concerns, including negative attitudes toward psychological help-seeking behavior (Vogel, Heimerdinger-Edwards, Hammer, \& Hubbard, 2011) often demonstrated in our sample by the inner conflict of male victims wanting to share with another person their traumatic and personal experience and yet remain anonymous. Research with male sexual assault victims suggests that "disclosure is rarely a discrete, one-time event, but rather a complicated, extended process" (Easton et al., 2014, p. 468), which may inform the many documented long pauses during conversations, avoidance of questions, and the frequent and abrupt hang-ups by male victims.

Given that males are often sexually abused by other men, survivors may experience a compounded sense of shame and stigma due to homophobia (Holmes et al., 1997) and fear being viewed as a victim or a homosexual (Alaggia, 2005). Conversely, men who openly identify as gay or bisexual are more likely to report sexual assault to law enforcement and seek supportive services (Bullock \& Beckson, 2011). Many of the internal emotions shared by our sample such as guilt, shame, and self-blame align with results from previous studies (Goodman-Brown, Edelstein, Goodman, Jones, \& Gordon, 2003; Hershkowitz, Lanes, \& Lamb, 2007). Our results suggest male victims of sexual assault may be negatively affected by societal attitudes toward masculinity 
and victimhood, which act as powerful deterrents to disclosure and help seeking for male survivors.

External barriers may also hinder male survivors of sexual assault to pursue supportive services as they are largely designed to address the treatment needs of females (Hooper \& Warwick, 2006), which is reinforced in our sample by the heightened awareness female survivors had of services available to them. Clinicians may also have biases or a lack of training that hinder the assessment and treatment of male victims of sexual assault (Lab, Feigenbaum, \& De Silva, 2000). Another barrier to disclosure and treatment seeking behavior for male victims is the process of naming and identifying the abuse experience (Sorsoli et al., 2008; Weiss, 2009). Many men who meet objective criteria for sexual assault do not label the experience as sexual abuse, possibly due to lack of awareness of legal definitions or minimization of the incident (Sorsoli et al., 2008), which may explain the high frequency of conversations around boundaries and seeking clarification on what constituted sexual assault. If victims downplay sexual assault as inadvertent or not-so-bad, they create a non-crime narrative that requires no formal action to be taken (e.g., reporting the incident to police, seeking supportive services, etc.; Weiss, 2009). By not recognizing wrongdoing, male victims are able to deny their victimhood and preserve their sense of power and control (Doherty \& Anderson, 2004). Crafting such narratives may help men feel a sense of control from the immediate emotional aftermath of trauma, but the long-term effects of these narratives may not be beneficial as these accounts concurrently excuse offenders while inadvertently transmitting blame back to the victims. If male survivors of sexual assault deny the existence of a crime or assume responsibility for the offense, their sense of shame and self-blame may discourage help seeking for their medical and emotional needs (Weiss, 2009).

\section{Contrasting Male and Female Caller Themes}

In summary, specific themes identified between male and female survivors of sexual assault appear diametrically opposed. For example, females were open about their thoughts and feelings as they regularly expressed concern about being drugged or having thoughts of self-harm. Males, however, had difficulty expressing their thoughts and feelings but conveyed a distrust of friends, family members, and professionals. While females voiced specific fears about "being believed," this was notably not a theme found for male callers. Instead, there were signs of a latent theme, fear of "being judged" for their victimhood based on documented behavior of male callers. Support for this distinction is added by the lack of personal disclosure by males to hotline workers, avoidance of questions, long pauses in conversation, and frequent and abrupt hang-ups while talking with hotline workers.

\section{Implications}

This study is a first step in understanding the experiences of male victim-survivors and their interactions with hotline services by comparing them with female victim-survivors. 
However, several opportunities to improve practice, develop and implement policy, and conduct future research are evident.

\section{Hotline Policies and Practices}

Implications for policy and practice include equipping hotline staff with knowledge to better equip responses that are uniquely empathetic, normalizing, and informed of common thoughts and feelings expressed by both male and female victim-survivors. Based on our findings, it may be appropriate for hotline workers to assess for social support in both male and female callers to identify key loved ones in their social networks whom survivors can readily access as sounding boards when experiencing emotional distress. In addition, workers should assess for thoughts of self-harm and suicide while on the phone call. Although only a few males in our sample mentioned having these type of thoughts, in general, males were more private concerning their emotional experiences from the rape and may have chosen not to discuss thoughts of self-harm. Research suggests survivors of sexual assault are at higher risk for suicide (Bryan, McNaughtonCassill, Osman, \& Hernandez, 2013; Chang \& Hirsch, 2015), and survivors who call the hotline seem to be in a critical point in their healing process. These discussions could prompt callers to think about their emotional needs in new ways and encourage survivors to widen their social support network or seek additional services.

Particularly, for male callers, the initial contact to the hotline is a critical opportunity to facilitate a positive experience, which may encourage further help-seeking behavior by this underserved population. To facilitate a positive experience, hotline workers should self-assess their own attitudes or biases about male victims of sexual assault and the potential impact it could have on male callers' future efforts of seeking help for their physical and mental health needs. Positive interactions may, in turn, facilitate further exploration by male callers and encourage acceptance of referrals for services. Fostering these positive interactions is particularly important for younger callers due to what we know about the long-term effects of assault. As part of these discussions, hotline workers should inform male victims about resource options, in addition to counseling, that can benefit them even if not prompted by the caller to do so. The knowledge of available resources may encourage eventual usage, even if not right away. Based on our findings, these resources may be more likely accessed by males if they are anonymous and/or one-on-one due to a distrust of others.

While there is much literature suggesting masculinity is a deterrent to help-seeking behavior (Mahalik et al., 2003; Vogel et al., 2011), qualities traditionally associated with men can also be utilized as strengths in the healing process. Men who identify with more conventional notions of masculinity may have strengths in areas such as problem solving, logical thinking, assertiveness, and risk-taking, which can be beneficial in times of crisis as outlined in the positive psychology/positive masculinity model by Kiselica and Englar-Carlson (2010). For example, problem solving and risk-taking (e.g., making changes in one's life or trying new behaviors, such as calling a hotline, that might be uncomfortable at first) can be used to positively influence the healing process and the caller's overall mental health. When speaking with male survivors, 
hotline workers can employ masculine-positive phrasing such as, "you are in control about what we talk about" or "you decide if you want to make changes in your life." In addition, hotline workers can link male survivors to the increasing number of online communities for men that provide information and anonymous support networks. These resources can help male victims recognize opportunities to receive support from people in their current social networks and larger community. Hotline workers can also assuage emotional weight male callers may be burdened with by exploring socially constructed norms of masculinity. An example being, "You mentioned thinking men shouldn't talk about their feelings. Can you tell me more about that?" Depending on the skill level of the hotline worker, they can explore the extent to which the sexual assault may have affected the survivor's association to sex, intimacy, and personal relationships with both men and women, as well as their own masculine identity.

\section{Community-Level Policies and Practices}

It is widely asserted that male sexual assault victims are far less likely than female sexual assault victims to report crimes against them (Holmes et al., 1997). Our findings suggest this discrepancy in reporting may be partially due to perceived judgment and distrust of others. In conjunction with less criminal reporting, there is less informal disclosure as well, as a high number of male callers remained anonymous. Those who sought formal support (i.e., counseling referrals, crisis counseling) regularly declined other resources, including legal services. Males who do seek criminal or civil actions often have worst legal outcomes than their female counterparts (Edelson \& Joa, 2010). For example, cases involving male victims are less likely to be filed with the District Attorney, and defendants are less likely to plead guilty to sexually abusing males (Edelson \& Joa, 2010). Perpetrators are more likely to commit sexual violence in communities where sexual violence goes unpunished (National Sexual Violence Resource Center, 2004). The systematic lack of services and support for male survivors of sexual assault perpetuates a feedback loop of increased risk of sexual violence in these communities and may make males a safer target with fewer negative consequences.

\section{Future Research and Limitations}

Continued research is needed to further explore the findings in this analysis. Due to our findings about men distrusting others and not providing personal information, rich data about the experiences of men may be gleaned from studies involving anonymous webbased services, such as online hotlines or chat rooms. In general, more research with larger samples from multiple resource centers is needed to better understand the male experience of sexual assault and treatment needs. In particular, factors that encourage men to self-disclose, seek professional and informal support, and aid in the healthy recovery process need to be identified. Archival data analysis also limits the ability to collect important demographic information (e.g., socioeconomic status, race, etc.) to contextualize these findings. Finally, practices applying the positive psychology/positive masculinity model (Kiselica \& Englar-Carlson, 2010) should be studied to examine its efficacy. 
As with all qualitative research, there are noteworthy limitations. First of all, readers must be discerning when attempting to generalize these findings. A potential weakness of qualitative research is that the researchers' own expectations, perceptions, and beliefs can influence the analysis of the data. To mitigate this threat, researchers worked as a team to analyze data and presented quotes to support how themes were interpreted. In addition, the written descriptions analyzed are from a second-hand source, and therefore, identified themes are an interpretation of the hotline workers' experience of the call. The narratives are limited by what the hotline worker thought was important to convey on the call sheet and are likely missing valuable information that could inform better practice.

\section{Conclusion}

The findings from this study are preliminary, exploratory, and far from exhaustive. Future research is needed for more of a comprehensive understanding of men's and women's sexual victimization experiences. Of particular importance, our findings highlight the need for expanding resources and the research knowledge base, as well as supportive services that account for the intricacies of being male and experiencing sexual assault.

\section{Declaration of Conflicting Interests}

The author(s) declared no potential conflicts of interest with respect to the research, authorship, and/or publication of this article.

\section{Funding}

The author(s) received no financial support for the research, authorship, and/or publication of this article.

\section{References}

Alaggia, R. (2005). Disclosing the trauma of child sexual abuse: A gender analysis. Journal of Loss \& Trauma, 10, 453-470. doi:10.1080/15325020500193895

Bierie, D. M., \& Davis-Siegel, J. C. (2015). Measurement matters: Comparing old and new definitions of rape in federal statistical reporting. Sexual Abuse: A Journal of Research and Treatment, 27, 443-459. doi:10.1177/1079063214521470

Black, M. C., Basile, K. C., Breiding, M. J., Smith, S. G., Walters, M. L., Merrick, M. T., . . . Stevens, M. R. (2011). The National Intimate Partner and Sexual Violence Survey (NISVS): 2010 summary report. National Center for Injury Prevention and Control. Retrieved from https://www.cdc.gov/violenceprevention/pdf/nisvs_report2010-a.pdf

Bogdan, R. C., \& Biklen, S. K. (1982). Qualitative research for education: An introduction to theory and methods (3rd ed.). Boston, MA: Allyn \& Bacon.

Bryan, C. J., McNaughton-Cassill, M., Osman, A., \& Hernandez, A. (2013). The associations of physical and sexual assault with suicide risk in nonclinical military and undergraduate samples. Suicide and Life-Threatening Behavior, 43, 223-234. doi:10.1111/sltb.12011

Bullock, C. M., \& Beckson, M. (2011). Male victims of sexual assault: Phenomenology, psychology, physiology. Journal of the American Academy of Psychiatry and the Law, 39, 197-205. doi:10.1016/j.bpobgyn.2012.08.011 
Bureau of Justice Statistics. (2012). Victimizations not reported to the police, 2006-2010. Retrieved from http://www.bjs.gov/index.cfm?ty=pbdetail\&iid $=4962$

Chang, E. C., \& Hirsch, J. K. (2015). Social problem solving under assault: Understanding the impact of sexual assault on the relation between social problem solving and suicidal risk in female college students. Cognitive Therapy and Research, 39, 403-413. doi:10.1007/ s10608-014-9664-2

Colvin, M. L., Pruett, J. A., Young, S. M., \& Holosko, M. H. (2016). An exploratory case study of a sexual assault telephone hotline: Training and practice implications. Violence Against Women. Advance online publication. doi:10.1177/1077801216654574

Creswell, J. W. (2007). Qualitative inquiry \& research design: Choosing among five approaches (2nd ed.). Thousand Oaks, CA: Sage.

Doherty, K., \& Anderson, I. (2004). Making sense of male rape: Constructions of gender, sexuality and experience of rape victims. Journal of Community \& Applied Social Psychology, 14, 85-103. doi:10.1002/casp.765

Easton, S. D., Saltzman, L. Y., \& Willis, D. G. (2014). "Would you tell under circumstances like that?" Barriers to disclosure of child sexual abuse for men. Psychology of Men \& Masculinity, 15, 460-469. doi:10.1037/a0034223

Edelson, M. G., \& Joa, D. (2010). Differences in legal outcomes for male and female children who have been sexually abused. Sexual Abuse: A Journal of Research and Treatment, 22, 427-442. doi:1079063210375973v1

Elliott, D., Bjelajac, P., Fallot, R., Markoff, L., \& Reed, B. (2005). Trauma-informed or traumadenied: Principles and implementation of trauma-informed services for women. Journal of Community Psychology, 33, 461-477. doi:10.1002/jcop.20063

Elliott, D., Mok, D., \& Briere, J. (2004). Adult sexual assault: Prevalence, symptomatology and sex differences in the general population. Journal of Traumatic Stress, 17, 208-211. doi:10.1023/B:JOTS.0000029263.11104.23

Finn, J., Garner, M. D., \& Wilson, J. (2011). Volunteer and user evaluation of the National Sexual Assault Online Hotline. Evaluation and Program Planning, 34, 266-272. doi:10.1016/j. evalprogplan.2010.09.002

Finn, J., \& Hughes, P. (2008). Evaluation of the RAINN National Sexual Assault Online Hotline. Journal of Technology in Human Services, 26, 203-222. doi:10.1080/15228830802094783

Frazier, P. (1993). A comparative study of male and female rape victims seen at a hospital-based rape crisis program. Journal of Interpersonal Violence, 8, 64-76. doi:10.1177/088626093008001005

Goodman-Brown, T. B., Edelstein, R. S., Goodman, G. S., Jones, D. P. H., \& Gordon, D. S. (2003). Why children tell: A model of children's disclosure of sexual abuse. Child Abuse \& Neglect, 27, 525-540. doi:10.1016/S0145-2134(03)00037-1

Guba, E., \& Lincoln, Y. (2005). Paradigmatic controversies, contradictions, and emerging influences. In N. Denzin \& Y. Lincoln (Eds.), The SAGE handbook of qualitative research (3rd ed., pp. 191-215). Thousand Oaks, CA: Sage.

Hershkowitz, I., Lanes, O., \& Lamb, M. E. (2007). Exploring the disclosure of child sexual abuse with alleged victims and their parents. Child Abuse \& Neglect, 31, 111-123.

Holmes, G. R., Offen, L., \& Waller, G. (1997). See no evil, hear no evil, speak no evil: Why do relatively few male victims of childhood sexual abuse receive help for abuse-related issues in adulthood? Clinical Psychology Review, 17, 69-88. doi:10.1016/S0272-7358(96)00047-5

Hooper, C. A., \& Warwick, I. (2006). Gender and the politics of service provision for adults with a history of childhood sexual abuse. Critical Social Policy, 26, 467-479. doi: $10.1177 / 0261018306062596$ 
Kiselica, M. S., \& Englar-Carlson, M. (2010). Identifying, affirming, and building upon male strengths: The positive psychology/positive masculinity model of psychotherapy with boys and men. Psychotherapy: Theory, Research, Practice, Training, 47, 276-287. doi:10.1037/ a0021159

Krebs, C. P., Linquist, C. H., Wanrner, T. D., Fisher, B. S., \& Martin, S. L. (2009). College women's experiences with physically forced, alcohol- or other drug-enabled, and drugfacilitated sexual assault before and since entering college. Journal of American College Health, 57, 639-647. doi:10.3200/JACH.57.6.639-649

Lab, D., Feigenbaum, J., \& De Silva, P. (2000). Mental health professionals' attitudes and practices towards male childhood sexual abuse. Child Abuse \& Neglect, 24, 391-409. doi:10.1016/S0145-2134(99)00152-0

Lisak, D. (1994). The psychological consequences of childhood abuse: Content analysis of interviews with male survivors. Journal of Traumatic Stress, 7, 525-548. doi:10.1002/ jts. 2490070403

Mahalik, J. R., Locke, B. D., Ludlow, L. H., Diemer, M. A., Scott, R. P. J., Gottfried, M., \& Freitas, G. (2003). Development of the Conformity to Masculine Norms Inventory. Psychology of Men \& Masculinity, 49, 3-25. doi:10.1037/1524-9220.4.1.3

Marshall, C., \& Rossman, G. B. (1999). Designing qualitative research (3rd ed.). Thousand Oaks, CA: Sage.

McLean, I. A. (2013). The male victim of sexual assault. Best Practice \& Research Clinical Obstetrics \& Gynaecology, 27, 39-46. doi:10.1016/j.bpobgyn.2012.08.006

Monk-Turner, E., \& Light, D. (2010). Male sexual assault and rape: Who seeks counseling? Sexual Abuse: A Journal of Research and Treatment, 22, 255-265. doi:10.1177/1079063210366271

National Sexual Violence Resource Center. (2004). Global perspectives on sexual violence: Findings from the world report on violence and health. Retrieved from http://www.nsvrc. org/sites/default/files/Publications_NSVRC_Booklets_Global-perspectives-on-sexualviolence.pdf

Rape, Abuse \& Incest National Network. (2013). RAINN annual report FYI. Retrieved from https://www.rainn.org/files/uploadedFiles/RAINN-FY13-Annual-Report.pdf

Rapport, F. (2010). Summative analysis: A qualitative method for social science and health research. International Journal of Qualitative Methods, 9, 270-290. doi:10.1177/160940691000900303

Resnick, H. S., Acierno, R., Kilpatrick, D. G., \& Holmes, M. (2005). Description of an early intervention to prevent substance abuse and psychopathology in recent rape victims. Behavior Modification, 29, 156-188. doi:10.1177/0145445504270883

Riggs, N., Houry, D., Long, G., Markovchick, V., \& Feldhaus, K. M. (2000). Analysis of 1,076 cases of sexual assault. Annals of Emergency Medicine, 35, 358-362. doi:10.1016/S01960644(00)70054-0

Ryan, G. W., \& Bernard, H. R. (2003). Techniques to identify themes. Field Methods, 15, 85109. doi: $10.1177 / 1525822 \times 02239569$

Shenton, A. (2003). Strategies for ensuring trustworthiness in qualitative research projects. Education for Information, 22, 63-75.

Sorsoli, L., Kia-Keating, M., \& Grossman, F. K. (2008). "I keep that hush-hush": Male survivors of sexual abuse and the challenges of disclosure. Journal of Counseling Psychology, 55, 333-345. doi:10.1037/0022-0167.55.3.333

Stemple, L., \& Meyer, I. (2014). The sexual victimization of men in America: New data challenge old assumptions. American Journal of Public Health, 104(6), e19-e26. doi:10.2105/ AJPH.2014.301946 
Tjaden, P., \& Thoennes, N. (2006). Extent, nature, and consequences of rape victimization: Findings from the National Violence Against Women Survey (Report NCJ 210346). Washington, DC: National Institute of Justice. Retrieved from https://www.ncjrs.gov/pdffiles $1 /$ nij/210346.pdf

U.S. Census Bureau. (2014). State and county quick facts. Retrieved from http://quickfacts. census.gov/qfd/states/13/13059.html

Vogel, D. L., Heimerdinger-Edwards, S. R., Hammer, J. H., \& Hubbard, A. (2011). "Boys don't cry": Examination of the links between endorsement of masculine norms, self-stigma, and help-seeking attitudes for men from diverse backgrounds. Journal of Counseling Psychology, 58, 368-382. doi:10.1037/a0023688

Wasco, S. M., Campbell, R., Howard, A., Mason, G. E., Staggs, S. L., Schewe, P. A., \& Riger, S. (2004). A statewide evaluation of services provided to rape survivors. Journal of Interpersonal Violence, 19, 252-263. doi:10.1177/0886260503260246

Weiss, K. G. (2009). "Boys will be boys" and other gendered accounts: An exploration of victims' excuses and justifications for unwanted sexual contact and coercion. Violence Against Women, 14, 786-808. doi:10.1177/1077801209333611 